\title{
Influence of immediate postpartum contraception counseling on the rate of unintended pregnancy in primigravida: a randomized controlled study
}

\author{
Mohammed Khalaf ${ }^{1}$, Shaymaa S. Abd El-kader², Ahmed M. Abbas ${ }^{1 *}$, \\ Hazem S. Mohamed ${ }^{1}$, Hassan S. Kamel ${ }^{1}$
}

\begin{abstract}
${ }^{1}$ Department of Obstetrics and Gynecology, Woman's Health Hospital, Faculty of Medicine, Assiut University, Egypt
${ }^{2}$ Department of Obstetrics and Gynecology, Assiut Hospital of Obstetrics and Gynecology, Egypt
\end{abstract}

Received: 15 September 2018

Accepted: 11 October 2018

\section{*Correspondence:}

Dr. Ahmed M. Abbas,

E-mail: bmr90@hotmail.com

Copyright: () the author(s), publisher and licensee Medip Academy. This is an open-access article distributed under the terms of the Creative Commons Attribution Non-Commercial License, which permits unrestricted non-commercial use, distribution, and reproduction in any medium, provided the original work is properly cited.

\section{ABSTRACT}

Background: The current study aims to assess the influence of immediate postpartum counselling about effective contraceptive methods to be used by primigravida on the rate of unintended pregnancy during first 6 months postpartum.

Methods: The study was a prospective randomized controlled trial for assessment the influence of immediate postpartum counseling about effective contraceptive methods to be used by primigravida on the rate of unintended pregnancy during first 6 months post-partum who delivered at the period between the 1st of December 2016 and 31 st of December 2017. The study patients were randomly assigned into two groups: Group (A) were received counseling about contraceptive methods using illustrations through postpartum interview with the study researcher. Group (B) were not received any counseling about contraceptive methods. The primary outcome was the difference in the rate of unintended pregnancy in both groups.

Results: No significant difference between both groups in preventing unintended pregnancy. In group (A): After 3 months postpartum 140 women $(93.3 \%)$ were used the contraceptive method correctly. 10 women used method incorrectly and 2 of them get pregnant. After 6 months postpartum 8 women did not use any method but 134 women $(95.7 \%)$ were correctly used the contraceptive method. In group (B): After 3 months postpartum 127 women (84.7\%) were used the contraceptive method correctly. 23 women used method incorrectly and 4 of them get pregnant. After 6 months postpartum 1 woman did not use any method but 30 women $(20.7 \%)$ were incorrectly used the contraceptive method.

Conclusions: Immediate post-partum counseling about contraceptive methods is good tool to educate women who intend to have optimal inter-pregnancy period about the effective methods that suit them and when to initiate.

Keywords: Contraception, Counseling, Family planning, Postpartum

\section{INTRODUCTION}

Almost one in thirteen women presenting with abortion or giving birth has conceived within 1 year of giving birth. Yet the survey suggests that the vast majority of postnatal women do not plan on having another pregnancy within the next year. This suggests that we are failing to meet the contraceptive need of women postpartum. Most women had not discussed ongoing contraception during the pregnancy with a health professional and most were unsure about what method they would use. ${ }^{1}$ Several factors influence a woman's 
decision on when to have another child. These factors may include her age, fertility, child care support, and economic and social circumstances.

Another important factor that should be considered in timing of another pregnancy is the potential health implications. A birth-to-pregnancy interval of less than 6 months is associated with elevated risk of maternal morbidity and mortality. A birth-to-pregnancy interval less than 18 months is associated with elevated risk of infant, neonatal, perinatal mortality, low-birth weight, small for gestational age and pre-term delivery. ${ }^{2}$

Guidelines from the National Institute for Health and Care Excellence (NICE) state that method and timing of contraception should be discussed in the first week postpartum, although they provide no guidance about the content of this discussion. The Faculty of Sexual and Reproductive Health care guidelines advice that time should be found in both the antenatal and postnatal period to discuss all forms of contraception.

However, a large internet survey of UK mothers found widespread dissatisfaction with the timing and quality of contraceptive advice received postnatal. Although traditionally contraception is discussed at the 6-week postpartum, fertility may have returned by this time for women who are not exclusively breastfeeding. ${ }^{1}$

Egyptian demographic heath survey (EDHS) (2014) had shown that knowledge of family planning methods is universal among currently married women in Egypt. ${ }^{3}$ Almost all currently married women age 15-49 years interviewed in the EDHS had good knowledge of the pill, IUDs, and injections, and $90.4 \%$ were aware of implants. $73.8 \%$ were aware of female sterilization, and almost $49.7 \%$ knew about the condom. Other methods were less widely recognized.

Only $19.6 \%$ knew about vaginal methods, $14.3 \%$ knew about male sterilization, and around $7.1 \%$ were aware of emergency contraception. ${ }^{3}$

Unwanted pregnancies are not only the major cause of maternal mortality and morbidity but are also a great social and financial burden on societies and countries. According to WHO statistics there are an estimated 200 million pregnancies around the world each year, and a third of these, 75 million, are unwanted.

Unintended pregnancy also is a major health problem in the United States of America. In the 2002 National Survey of Family Growth assessment, 1.22 million, or $31 \%$, were reported as unintended.

When abortions were included, unintended pregnancies increased to 2.65 million, or $49 \%$ of all pregnancies. ${ }^{4}$ The aim of this study was to assess the influence of immediate postpartum counseling about effective contraceptive methods to be used by primigravida on the rate of unintended pregnancy during first 6 months post-partum.

\section{METHODS}

Study design: The study was a prospective randomized controlled trial for assessment the influence of immediate postpartum counseling about effective contraceptive methods to be used by primigravida on the rate of unintended pregnancy during first 6 months post-partum who delivered at the period between the $1^{\text {st }}$ of December 2016 and $31^{\text {st }}$ of December 2017. This RCT registered, open labeled, randomized controlled trial (Clinical Trials.gov ID: NCT02901639)

Study setting and duration: Women's Health University Hospital and Assiut hospital for obstetrics, gynecology and pediatrics (Al Eman) between the 1st of December 2016 and 31st of December 2017.

Patients: All primigravidae women were delivered in both hospitals during the study period were enrolled in the study.

\section{Inclusion criteria}

- Age: above 18 years

- Primigravida

- Women who will accept to participate in the study.

\section{Exclusion criteria}

- Women not intended to use contraception

- Multiparous

- Women who refuse to participate in the study.

\section{Methodology}

The study patients were randomly assigned into two groups:

Group (A) were received counseling about contraceptive methods using illustrations through postpartum interview with the study researcher

Group (B) were not received any counseling about contraceptive methods

\section{Randomization}

Randomization was conducted using a computergenerated table of random numbers with allocation concealment.

Allocation concealment will be done using seriallynumbered closed opaque envelope. Counseling for participation was done before recruitment. Once allocation has been done, it could not be changed. 


\section{Study intervention}

Participants, after informed consent, were randomized in a 1:1 ratio to the two groups. The researcher used a version of the WHO Decision-Making Tool (DMT) for Family Planning in one-to-one interview in the postpartum day before hospital discharge. The DMT is a double-sided visual aid that presents the available contraceptives, provides information regarding medical eligibility criteria and possible side effects of each method, and advises on when to seek medical care. Each contraceptive method was available during the encounters for patients to feel and visualize each possibility.

The following recommendations applied to women who wanted contraception, regardless of whether they were breast-feeding:

Contraceptive advice should be provided after delivery, to prevent unwanted or closely spaced pregnancies and the obstetric and neonatal risks associated with them (grade C). Effective contraception should begin no later than 21 days after delivery (grade B). Combined contraceptive pills should not be used before 6 weeks post-partum (grade B).

The risk-benefit balance of this use between the 6th and 12th weeks post-partum was assessed for women with vascular risk factors. Progestin-only contraceptives (oral or implants) proposed from the immediate postpartum period (grade B). If an IUD is the contraceptive method chosen, it was prescribed at discharge from the maternity unit so that it was placed at the postnatal consultation (grade B). Long-term contraceptive methods, such as implants or IUDs, were preferred for women at risk of being lost to follow-up, with an assessment of the riskbenefit balance of each method.

The demographic, socioeconomic, and educational/ professional background of the women and their partners were recorded. Parity and number of antenatal visits of these women, their knowledge/ awareness of contraception, their responses to contraceptive counselling, and the reasons for refusal was also recorded.

A prepared data sheet that included all this information will be used to record each woman's data and response. All patients were followed up at 3 months and 6 months to assess the rate of correct use of contraceptive methods, the rate of LAM, and the rate of occurrence of unintended pregnancy during the first 6-months postpartum

\section{Outcomes}

\section{Primary Outcome}

The difference in the rate of unintended pregnancy in both groups

\section{Secondary outcomes}

The rate of use of LAM. The rate of correct use of different contraceptive methods

\section{Sample size}

Sample size was calculated using the Open Epi software program, version 2.3.1. The rate of unintended pregnancy among breastfeeding women in the same setting in Assiut was 27\%.5

Authors hypothesized that counselling will reduce this rate by $50 \%$. Using two-sided chi-square $\left(\chi^{2}\right)$ test with $\alpha$ of 0.05 , a total sample size of at least 276 women in both groups (138 in each group) using $80 \%$ power was necessary to detect $50 \%$ reduction in unintended pregnancy rate (Odds Ratio $=0.42$ ).

Assuming a rate of loss of follow-up of $10 \% .150$ women in each arm were included.

\section{Statistical analysis}

All data analyzed using SPSS software Chicago, IL, USA, version 21. Comparison between categorical variables in both groups was done by Chi-square test and continuous variables were compared using Student T-test. $\mathrm{P}$-value $<0.05$ was considered significant.

Ethical considerations:

- All the regulations of the local ethics committee of Faculty of Medicine, Assiut University were followed.

- All the patients had clear verbal and written description of the study.

- Only those providing informed consent were enrolled in the study.

\section{RESULTS}

Among the total sample $(\mathrm{N}=300)$, the mean age of women was $23.54 \pm 3.22$ years. $67.7 \%$ of women graduated sub-university and $81.3 \%$ did not work. There was $57.3 \%$ of women lived in rural areas and $42.7 \%$ in urban areas (Table 1).

There was no significant difference between both groups in preventing unintended pregnancy (UIP) as demonstrated in (Table 2).

The rate of use of contraceptive methods was similar between both groups at 3 months postpartum except for the rate of LAM which was higher in no-counselling group $(p=0.000)$, and the rate of IUD use which was significantly higher in the counselling group $(p=0.001)$. after 6 months, the rate of use of LAM was similarly higher in no counselling group $(\mathrm{p}=0.000)$, while the rate 
of use of POPs and IUD was significantly higher in counseling group (Table 3 ).

Table 1: Socio-demographic characteristics of women.

\begin{tabular}{|c|c|c|}
\hline Variables & No. $(n=300)$ & $\%$ \\
\hline \multicolumn{3}{|l|}{ Age (years) } \\
\hline$<22$ & 85 & 28.3 \\
\hline $22-30$ & 203 & 67.7 \\
\hline$>30$ & 12 & 4.0 \\
\hline Mean \pm SD (Range) & \multicolumn{2}{|c|}{$23.54 \pm 3.22(20.0-35.0)$} \\
\hline \multicolumn{3}{|l|}{ Education } \\
\hline Illiterate & 44 & 14.7 \\
\hline Sub-university & 203 & 67.7 \\
\hline University & 53 & 17.7 \\
\hline \multicolumn{3}{|l|}{ Occupation } \\
\hline Working & 56 & 18.7 \\
\hline Not working & 244 & 81.3 \\
\hline \multicolumn{3}{|l|}{ Husband age } \\
\hline$<25$ & 52 & 17.3 \\
\hline $25-<30$ & 149 & 49.7 \\
\hline$\geq 30$ & 99 & 33.0 \\
\hline Mean \pm SD (Range) & \multicolumn{2}{|c|}{$27.77 \pm 4.36(19.0-55.0)$} \\
\hline \multicolumn{3}{|l|}{ Husband education } \\
\hline Illiterate & 40 & 13.3 \\
\hline Sub-university & 201 & 67.0 \\
\hline University & 59 & 19.7 \\
\hline \multicolumn{3}{|c|}{ Husband occupation } \\
\hline Employee & 65 & 21.7 \\
\hline Farmer & 36 & 12.0 \\
\hline Worker & 133 & 44.3 \\
\hline Free business & 66 & 22.0 \\
\hline \multicolumn{3}{|l|}{ Residence } \\
\hline Rural & 172 & 57.3 \\
\hline Urban & 128 & 42.7 \\
\hline \multicolumn{3}{|l|}{ Years of marriage } \\
\hline One year & 123 & 41.0 \\
\hline More than one year & 177 & 59.0 \\
\hline Marital life & & $\%$ \\
\hline Regular & 263 & 87.7 \\
\hline Irregular & 37 & 12.3 \\
\hline
\end{tabular}

Table 2: The rate of unintended pregnancy in both groups.

\begin{tabular}{|c|c|c|c|c|c|}
\hline \multirow[t]{2}{*}{ Pregnancy } & \multicolumn{2}{|c|}{$\begin{array}{l}\text { Counseling } \\
(n=150)\end{array}$} & \multicolumn{2}{|c|}{$\begin{array}{l}\text { No counseling } \\
(\mathrm{n}=150)\end{array}$} & \multirow{2}{*}{$\begin{array}{l}\text { P- } \\
\text { value }\end{array}$} \\
\hline & No. & $\%$ & No. & $\%$ & \\
\hline \multicolumn{5}{|l|}{ After 3 m } & \multirow{3}{*}{0.680} \\
\hline Yes & 2 & 1.3 & 4 & 2.7 & \\
\hline No & 148 & 98.7 & 146 & 97.3 & \\
\hline After 6 m & \multicolumn{2}{|c|}{$(n=148)$} & \multicolumn{2}{|c|}{$(n=146)$} & \multirow{3}{*}{0.232} \\
\hline Yes & 12 & 8.1 & 18 & 12.3 & \\
\hline No & 136 & 91.9 & 128 & 87.7 & \\
\hline
\end{tabular}

In group (A): After 3 months postpartum 140 women $(93.3 \%)$ were used the contraceptive method correctly. 10 women used method incorrectly and 2 of them get pregnant. After 6 months postpartum 8 women did not use any method but 134 women $(95.7 \%)$ were correctly used the contraceptive method.

In group (B): After 3 months postpartum 127 women $(84.7 \%)$ were used the contraceptive method correctly. 23 women used method incorrectly and 4 of them get pregnant.

Table 3: The rate of use of contraceptive methods in both groups.

\begin{tabular}{|c|c|c|c|c|c|}
\hline \multirow{2}{*}{$\begin{array}{l}\text { Contraceptive } \\
\text { methods }\end{array}$} & \multicolumn{2}{|c|}{$\begin{array}{l}\text { Counseling } \\
(n=150)\end{array}$} & \multicolumn{2}{|c|}{$\begin{array}{l}\text { No counseling } \\
(\mathrm{n}=150)\end{array}$} & \multirow{2}{*}{$\begin{array}{l}\text { P- } \\
\text { value }\end{array}$} \\
\hline & No. & $\%$ & No. & $\%$ & \\
\hline \multicolumn{6}{|l|}{ After 3 m } \\
\hline LAM & 42 & 28.0 & 79 & 52.7 & $0.000^{*}$ \\
\hline POPs & 45 & 30.0 & 33 & 22.0 & 0.114 \\
\hline IUD & 36 & 24.0 & 14 & 9.3 & $0.001 *$ \\
\hline Implanon & 16 & 10.7 & 11 & 7.3 & 0.313 \\
\hline COCS & 10 & 6.7 & 8 & 5.3 & 0.627 \\
\hline Depo-provera & 1 & 0.7 & 5 & 3.3 & 0.214 \\
\hline After $6 \mathrm{~m}$ & \multicolumn{2}{|c|}{$(n=148)$} & \multicolumn{2}{|c|}{$(n=146)$} & \\
\hline None & 8 & 5.4 & 1 & 0.7 & $0.036^{*}$ \\
\hline LAM & 14 & 9.5 & 55 & 37.7 & $0.000 *$ \\
\hline POPs & 58 & 39.2 & 37 & 25.3 & $0.001 *$ \\
\hline IUD & 40 & 27.0 & 22 & 15.1 & $0.012 *$ \\
\hline Implanon & 16 & 10.8 & 12 & 8.2 & 0.449 \\
\hline COCS & 11 & 7.4 & 14 & 9.6 & 0.507 \\
\hline Depo-provera & 1 & 0.7 & 5 & 3.4 & 0.119 \\
\hline
\end{tabular}

After 6 months postpartum 1 woman did not use any method but 30 women $(20.7 \%)$ were incorrectly used the contraceptive method. Counseling was significant in using contraceptive methods correctly compared to using the method without counseling $(\mathrm{P}=0.000)$ (Table 4$)$.

Table 4: The correct use of contraceptive methods in both groups.

\begin{tabular}{|c|c|c|c|c|c|}
\hline \multirow{2}{*}{$\begin{array}{l}\text { Correct } \\
\text { use }\end{array}$} & \multicolumn{2}{|c|}{$\begin{array}{l}\text { Counseling } \\
(\mathrm{n}=150)\end{array}$} & \multicolumn{2}{|c|}{$\begin{array}{l}\text { No counseling } \\
(\mathrm{n}=150)\end{array}$} & \multirow[t]{2}{*}{ P-value } \\
\hline & No. & $\%$ & No. & $\%$ & \\
\hline \multicolumn{5}{|l|}{ After 3 m } & \multirow{3}{*}{$0.016^{*}$} \\
\hline Yes & 140 & 93.3 & 127 & 84.7 & \\
\hline No & 10 & 6.7 & 23 & 15.3 & \\
\hline After $6 \mathrm{~m}$ & \multicolumn{2}{|c|}{$(n=140)$} & \multicolumn{2}{|c|}{$(n=145)$} & \multirow{3}{*}{$0.000 *$} \\
\hline Yes & 134 & 95.7 & 115 & 79.3 & \\
\hline No & 6 & 4.3 & 30 & 20.7 & \\
\hline
\end{tabular}

\section{DISCUSSION}

Counseling is fundamental part of family planning services. ${ }^{6}$ It helps women to identify the different types of contraceptive methods that suit them and to know how and when they initiate the methods. Correct counseling means correct use of the method and more tolerate to side effects. Counseling is also important to promote 
lengthening birth pregnancy interval so decrease rate of UIP which may causes many neonatal and maternal morbidity and mortality. ${ }^{7}$

In present study socio-demographic characteristics of the studied subjects (age, education level, residence in rural or urban areas, duration of marriage, mode of delivery, and gender of the delivered baby) have no statistically significant on the rate of unintended pregnancy in both groups. Those results agreed with those of study of Yilmazel et al that showed no statistically significant relation between women about using postpartum contraceptive method with their ages, levels of education, husbands' levels of education, duration of marriage. ${ }^{4}$

In this study there is no significant difference between counseled and non-counseled women on rate of unintended pregnancy $(\mathrm{P}=0.232)$ because during the study period some women discontinue contraceptive method because they desired to get pregnant or received wrong rumors about how to tolerate side effects of the contraceptive method. But counseling was helpful factor in decreasing rate of UIP and its health hazards. women who get pregnant after 6 months postpartum where 36 women $(12 \%)$ of the studied primipara women (300). 14 women $(4.7 \%)$ of them received immediate postpartum counseling about contraception compared to 22 women $(7.3 \%)$ did not counseled about contraception.

The 2014 EDHS3 showed that $16 \%$ of births in the fiveyear period were not wanted at the time of conception. This percentage is slightly higher than the percentage of women who reported an unwanted birth in the 2008 EDHS (14\%). This demonstrates the importance of enhancement contraceptive counseling to face unmet needs of family planning services and decrease rate of UIP in Egypt.

The 2014 EDHS showed that around 3 in 10 family planning users in Egypt stop using the contraceptive methods within 12 months of starting use. Side effects and health concerns are the reasons for stopping the method (11 percent). In the present study, Counseling helped woman to use their chosen contraceptive methods correctly by $(93.3 \%)$ after 3 months postpartum and when they re-counseled after another 3 months the correct use increased to $(95.7 \%)$ but women who did not received any counseling, their correct use after 3 months postpartum was $(84.7 \%)$ and after 6 months declined to $(79.3 \%)$ due to in toleration to side effects, myths and improper information about how to use methods.

In this study there was significant relation between counseling and using copper IUD as long acting contraceptive methods (LARC). 62 women (21.1\%) of the studied women used long acting contraceptive method (copper IUD), 40 of them received postpartum contraceptive counseling compared to 22 women used IUD in non-counseling group. Counseling increased awareness about long acting contraceptive methods
(LARC) and correct misunderstandings. That was agreed with the study of Yilmazel et al which showed that IUD was the most preferred postpartum contraceptive method by pregnant women $(35.7 \%)$. Reasons such as being safe, no load to users and using for a long time can contribute to IUD to be more preferred than other methods. ${ }^{4}$

\section{Lactational amenorrhea method (LAM)}

One of the most traditional contraceptive methods in Egypt. ${ }^{8}$ In present study 287 women $(95.7 \%)$ of the studied women were exclusively breast feeding and 13 women $(4.3 \%)$ their children were in NICU or severely ill and neonatologist prescribed artificial feeding. After 3 months postpartum 121 women $(40.3 \%)$ dependent on LAM as contraceptive method then declined after 6 months to only 69 women $(23.5 \%)$.

Women in the counseling group were less dependent on LAM as a method of contraception (42 women of 121 in the first 3 months postpartum and declined to 14 women of 69 in the first 6 months postpartum) compared to (79 women of 121 in the first 3 months postpartum and declined to 55 of 69 in the first 6 months postpartum). Those women preferred to use method with low failure rate and be aware that when any of these 3 criteria of LAM was lost nothing means LAM and she need another contraceptive method. So, counseling was significant in decreasing rate of UIP in women using LAM. ${ }^{9}$

The 2014 EDHS showed that few women were aware of the comparatively short period after birth during which breastfeeding may afford a woman protection from pregnancy. Only 7 percent of the women reported correctly that a woman is only protected from a pregnancy during the first 6 months that she breastfeeds her child. More than one-quarter of women ( 28 percent) thought that a breastfeeding mother is protected from pregnancy until her period returned, and slightly less than 30 percent believed that a mother is protected until the child is weaned.

According to the results of study of (Shaaban and Glasier), more than $95 \%$ of women breastfed the child before their current pregnancy; $25.3 \%$ conceived while breastfeeding. ${ }^{5}$ Conception occurred during the first 6 months postpartum in $4.4 \%$, before resumption of menstruation in $15.1 \%$ and while exclusively or almost exclusively breastfeeding in $28.1 \%$. Only 10 pregnancies $(1.5 \%)$ occurred when all the prerequisites of the lactational amenorrhea method of contraception (LAM) were present. Twenty-nine percent of pregnancies conceived during breastfeeding were unintended, $10 \%$ of women had considered terminating their pregnancy while $4.4 \%$ of them reported trying to do so. Pregnancy during breastfeeding is common in Egypt and is often unintended. There is great potential for using LAM, but it must be properly taught, and women should be encouraged to start using effective contraception as soon as any of the prerequisites of LAM expires..$^{8,10}$ 


\section{CONCLUSION}

Immediate post-partum counseling about contraceptive methods is good tool to educate women who intend to have optimal inter-pregnancy period about the effective methods that suit them and when to initiate. Counseling promotes correct use of different methods and enhances their continuation. LAM is the most traditional contraceptive method but to decrease its high failure rate good counseling about its strict requirements should be done for women who depend on it. Counseling is helpful factor to decrease rate of unintended pregnancy and its adverse outcomes.

Funding: No funding sources

Conflict of interest: None declared

Ethical approval: The study was approved by the Institutional Ethics Committee

\section{REFERENCES}

1. Heller R, Cameron S, Briggs R, Forson N, Glasier A. Postpartum contraception: a missed opportunity to prevent unintended pregnancy and short interpregnancy intervals. J Fam Plann Reproduct Health Care. 2016;42(2):93-8.

2. Hani A, Moss M, Cooper D, Morroni C, Hoffman M.Informed choice- the timing of postpartum contraceptive initiation. S Afr Med J 2003;93(11):862-4.

3. EDHS; Ministry of Health and Population [Egypt], El-Zanaty and Associates [Egypt], and ICF International. 2015. Egypt Demographic and Health Survey 2014. Cairo, Egypt and Rockville, Maryland, USA: Ministry of Health and Population and ICF International.

4. Yilmazel G, Balci E. Preferences and related factors for postpartum contraception in pregnant women. Iranian J Reprod Med. 2011;11(10):801.

5. Shaaban OM, Glasier AF. Pregnancy during breastfeeding in rural Egypt. Contraception. 2008;77(5):350-4.
6. Kim YM, Kols A, Mucheke S. Informed choice and decision-making in family planning counseling in Kenya. International family planning perspectives. 1998:4-2.

7. Shaaban OM, Abbas AM, Hafiz HA, Abdelrahman AS, Rashwan M, Othman ER. Effect of pregnancylactation overlap on the current pregnancy outcome in women with substandard nutrition: a prospective cohort study. Facts, views and vision in Obstet Gynecol. 2015;7(4):213.

8. Shaaban OM, Abbas AM, Mahmoud HR, Yones EM, Hassen SG, Zakherah MS. Counseling and inadvance provision of levonorgestrel emergency contraceptive pills decrease the rate of unplanned pregnancy during breastfeeding: a randomized controlled trial. J Maternal Fetal Neonat Med. 2017:1-6.

9. Peterson AE, Peŕez-Escamilla R, Labboka MH, Hight V, Von Hertzen H, Van Look P. Multicenter study of the lactational amenorrhea method (LAM) III: effectiveness, duration, and satisfaction with reduced client-provider contact1. Contraception. 2000;62(5):221-30.

10. Shaaban OM, Abbas AM, Mahmoud HR, Yones EM, Mahmoud A, Zakherah MS. Levonorgestrel emergency contraceptive pills use during breastfeeding; effect on infants' health and development. J Maternal Fetal Neonat Med. 2018:15 .

Cite this article as: Khalaf M, El-kader SS, Abbas AM, Mohamed HS, Kamel HS. Influence of immediate postpartum contraception counseling on the rate of unintended pregnancy in primigravida: a randomized controlled study. Int J Reprod Contracept Obstet Gynecol 2018;7:4736-41. 